\title{
Renal Amyloidosis Following Chronic Osteomyelitis in a Patient with Congenital Insensitivity to Pain and Anhidrosis
}

\author{
Sevgi Yavuz*, Aydin Ece \\ Division of Pediatric Nephrology, Dicle University, Diyarbakir, Turkey \\ Email: ${ }^{*}$ drsyavuz@gmail.com
}

Received 24 July 2014; revised 20 August 2014; accepted 19 September 2014

Copyright $(\subseteq 2014$ by authors and Scientific Research Publishing Inc.

This work is licensed under the Creative Commons Attribution International License (CC BY).

http://creativecommons.org/licenses/by/4.0/

$$
\text { c) (i) Open Access }
$$

\begin{abstract}
Congenital insensitivity to pain and anhidrosis (CIPA) is a rare form of hereditary sensory and autonomic neuropathy. It is characterized by impaired perception of pain and temperature, anhidrosis and intellectual disability. Self mutilating behaviors lead to accidental injuries. The limb lesions are often infected and frequently progress to chronic osteomyelitis. In pediatrics, amyloidosis usually occurs secondary to chronic inflammatory diseases. The coexistence of amyloidosis and CIPA has not previously been reported in literature. A CIPA case complicated with nephrotic syndrome and renal amyloidosis following chronic osteomyelitis is presented here. This report emphasizes the importance of close follow-up of patients by urine analysis for the risk of developing amyloidosis particularly in the presence of chronic infections.
\end{abstract}

\section{Keywords}

Pain Insensitivity, Anhidrosis, Osteomyelitis, Nephrotic Syndrome, Amyloidosis

\section{Introduction}

Congenital insensitivity to pain and anhidrosis (CIPA), also known as hereditary sensory and autonomic neuropathy type IV (HSAN IV), is an autosomal recessive disorder caused by mutations in neuropathic tyrosine kinase receptor type 1 (NTRK1) gene encoding the nerve growth factor receptor [1]. The failure in differentiation and migration of neural crest cells leads to the complete absence of small myelinated and unmyelinated nerve fibers, thereby resulting in impaired pain perception and autonomic dysfunction. The characteristic clinical features of CIPA include recurrent episodes of unexplained pyrexia, anhidrosis, mental retardation and insensitivity

\footnotetext{
*Corresponding author.
}

How to cite this paper: Yavuz, S. and Ece, A. (2014) Renal Amyloidosis Following Chronic Osteomyelitis in a Patient with Congenital Insensitivity to Pain and Anhidrosis. Open Journal of Pediatrics, 4, 243-246. 
to pain with subsequent self-mutilation. Furthermore, patients often suffer from skin lacerations and fractures which are frequently complicated by persistent wound infections, septic arthritis and osteomyelitis [1] [2].

The amyloidosis is characterized by extracellular deposition of proteins in various tissues as insoluble fibrils. To date almost 25 different amyloid fibrils have been known to cause amyloidosis. In pediatrics, the most common form of amyloidosis is reactive AA amyloidosis secondary to chronic inflammatory diseases [3]-[5]. Here, we present a boy with CIPA who developed renal AA amyloidosis following chronic osteomyelitis.

\section{Case Report}

A 13-year-old boy was admitted with swelling throughout the body. He was the first child of consanguineous parents. The insensitivity to pain, self-mutilating behaviors, mental retardation, lack of sweating, unexplained fever and vomiting attacks were noticed during infancy. He experienced right femur fracture at 4 years old and consequently had several operations on his right leg. He frequently hospitalized for recurrent cellulitis and osteomyelitis for the last four years. Several courses of parenteral antibiotics and debridement of soft tissues had been performed. The orthopedists recommended right leg amputation, however this was not approved by his parents. He had a sister suffering from similar complaints. On physical examination, his weight and height were below the $3^{\text {rd }}$ percentile. He had generalized edema with a warm and thick skin. Palms and soles were hyperkeratotic. There was prominent scarring and tissue loss upon lips and fingertips due to biting. His right thigh was edematous and erythematous. He had miscellaneous trophic ulcers and chronic destructive changes on his knees (Figure 1). Neurological examination revealed mild hypotonia with insensitivity to superficial and deep pain stimuli. Laboratory investigations showed anemia (hgb: $10.9 \mathrm{~g} / \mathrm{dl}$ ), nephrotic range proteinuria (urine protein/ urine creatinine: $3 \mathrm{mg} / \mathrm{mg}$ ), hypoalbuminemia (albumin: $0.5 \mathrm{~g} / \mathrm{dl}$ ) and hyperlipidemia (total cholesterol: 216, triglyceride: $200 \mathrm{mg} / \mathrm{dl}$ ). Acute phase reactants were increased (erythrocyte sedimentation rate: $50 \mathrm{~mm} / \mathrm{h}$, C-reactive protein: $20 \mathrm{mg} / \mathrm{L}$ ). Renal (urea: $22 \mathrm{mg} / \mathrm{dl}$, serum creatinine: $0.4 \mathrm{mg} / \mathrm{dl}$ ) and liver function tests (ALT: 20 $\mathrm{mg} / \mathrm{dl}$, AST: $16 \mathrm{mg} / \mathrm{dl})$, serum complements $\left(\mathrm{C}_{3}: 98 \mathrm{mg} / \mathrm{dl}, \mathrm{C}_{4}: 16 \mathrm{mg} / \mathrm{dl}\right)$ ) and immunoglobulin levels were within normal limits. Both anti-nuclear antibody (ANA), anti-double stranded DNA (anti-DNA) and viral markers were negative. No mutation was detected on Familial Mediterranean Fever genetic analysis. Renal ultrasonography was normal. Electromyography (EMG) indicated polyneuropathy affecting motor and sensorial fibers. The patient showed no obvious pain with EMG needle insertion. The sural nerve biopsy showed degeneration in nerve fibers. A clinical diagnosis of CIPA was established. Genetic analysis was not made because of its unavailability in our country. Given the additional nephrotic syndrome, a renal biopsy was performed and the findings were consistent with renal amyloidosis (Figure 2). Immunosuppressive drugs were not given because of presence of chronic infection. Angiotensin converting enzyme inhibitor (ACEI) and lipid lowering agents were started. The patient required several parenteral antibiotics courses and albumin infusions. His parents persisted for not approving limb amputation. At the end of twelve months of follow-up, the patient progressed to

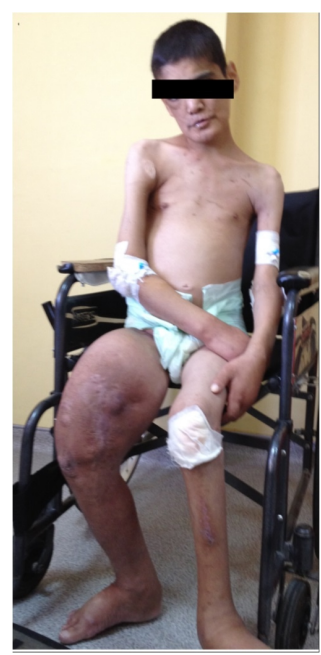

Figure 1. Photography of the patient showing generalized edema with edematous and erythematous right leg, miscellaneous trophic ulcers and chronic destructive changes on knees. 


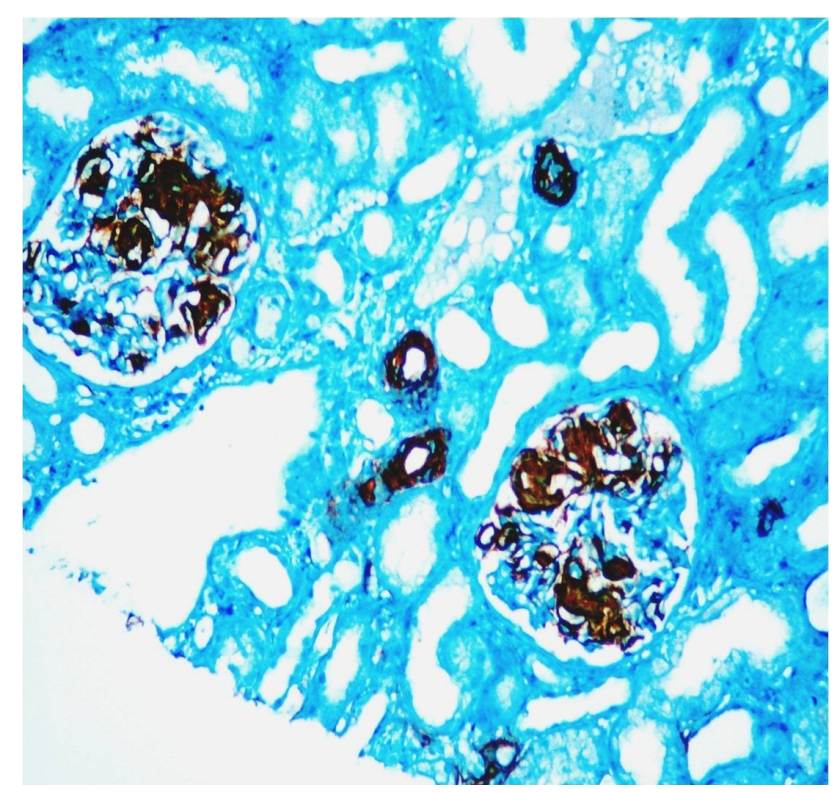

Figure 2. Positive immunoperoxidase staining for AA amyloid in glomerular mesangium and capillary walls $(\times 200)$.

chronic kidney disease (CKD) and was died due to septic shock.

\section{Discussion}

CIPA is a very rare form of hereditary sensory and autonomic neuropathy. To date, a few hundred cases have been described. Patients have a clinical triad of impaired perception of pain and temperature, anhidrosis and intellectual disability. Their lifespan is usually short. Hyperprexia and sepsis account for the death in vast majority of the patients [6]. The present case exhibited typical clinical picture of CIPA despite the lack of confirmation by genetic analysis. The sibling with similar medical history supported our opinion.

Orthopedic problems are one of the most characteristic and serious complications of CIPA. The insensitivity to pain leads to multiple accidental injuries. The limb lesions are often infected and frequently progress to chronic osteomyelitis, at times requiring limb amputation [7] as we observed in our patient. On the other hand the close relationship between longstanding infections including osteomyelitis and amyloidosis has been well described in literature [8] [9]. However, amyloidosis has not previously been reported in CIPA. The current CIPA case is the first that is complicated with renal amyloidosis probably due to chronic osteomyelitis.

The kidney is a major target organ for systemic amyloidosis. Asymptomatic proteinuria is the most common initial presentation of renal disease. Nephrotic syndrome occurs in more than one fourth of patients at the time of diagnosis [5]. Similarly, our patient was referred after the onset of nephrotic syndrome. Furthermore, the amount of proteinuria and renal function vary according to the extent and/or site of amyloid deposition [3]. Uda et al. reported that glomerular amyloid depositions are more common and have a worse prognosis compared to vascular and tubular depositions in rheumatoid arthritis-related AA amyloidosis [10]. Likewise, glomerular accumulation was more prominent and progression to renal dysfunction was accelerated in the present case.

The prognosis of renal amyloidosis is generally poor and usually progress to ESRD if untreated. The major therapeutic strategy is to suppress the inflammatory activity by specific treatment of underlying disorder [1]-[3]. The medical approach in our patient was a dilemma. We were unable to eliminate chronic osteomyelitis since the parents disapproved limb amputation. Palliative treatment with ACEI and albumin infusions was administered until CKD has developed. Prevention and training programmes were applied since no specific treatment for CIPA has been available. The skin was kept clean and moisture. The parents were trained to minimize the injuries.

\section{Conclusion}

In conclusion, the present CIPA case is the first case that is complicated with renal amyloidosis due to chronic 
osteomyelitis. This report emphasizes that patients with CIPA should be closely followed up by urine analysis for the risk of developing amyloidosis particularly in the presence of chronic infections.

\section{Conflict of Interest}

None.

\section{References}

[1] Indo, Y., Tsurata, M., Hayashida, Y., et al. (1996) Mutations in TRKA/NGF Receptor Gene in Patients with Congenital Insensitivity to Pain with Anhidrosis. Nature Genetics, 13, 485-488. http://dx.doi.org/10.1038/ng0896-485

[2] Sztriha, L., Lestringant, G.G., Hertecant, J., Frossard, P.M. and Masouyé, I. (2001) Congenital Insensitivity to Pain with Anhidrosis. Pediatric Neurology, 25, 63-66. http://dx.doi.org/10.1016/S0887-8994(01)00278-8

[3] Bilginer, Y., Akpolat, T. and Ozen, S. (2011) Renal Amyloidosis in Children. Pediatric Nephrology, 26, $1215-1227$. http://dx.doi.org/10.1007/s00467-011-1797-X

[4] Dember, L.M. (2006) Amyloidosis-Associated Kidney Disease. Journal of the American Society of Nephrology, 17, 3458-3471. http://dx.doi.org/10.1681/ASN.2006050460

[5] Nishi, S., Alchi, B., Imai, N. and Gejyo, F. (2008) New Advances in Renal Amyloidosis. Clinical and Experimental Nephrology, 12, 93-101. http://dx.doi.org/10.1007/s10157-007-0008-3

[6] Bonkowsky, J.L., Johnson, J., Carey, J.C., Smith, A.G. and Swoboda, K.J. (2003) An Infant with Primary Tooth Loss and Palmar Hyperkeratosis: A Novel Mutation in the $\mathrm{NTRK}_{1}$ Gene Causing Congenital Insensitivity to Pain with Anhidrosis. Pediatrics, 112, 237-241. http://dx.doi.org/10.1542/peds.112.3.e237

[7] Shorer, Z., Shaco-Levy, R., Pinsk, V., Kachko, L. and Levy, J. (2013) Variation of Muscular Structure in Congenital Insensitivity to Pain with Anhidrosis. Pediatric Neurology, 48, 311-313. http://dx.doi.org/10.1016/j.pediatrneurol.2012.12.015

[8] Odabas, A.R., Cetinkaya, R., Selcuk, Y., Erman, Z. and Bilen, H. (2002) Clinical and Biochemical Outcome of Renal Amyloidosis. International Journal of Clinical Practice, 56, 342-344.

[9] Tuglular, S., Yalcinkaya, F.I., Paydas, S., et al. (2002) A retrospective Analysis of 287 Secondary Amyloidosis Cases in Turkey. Nephrology Dialysis Transplantation, 17, 2003-2005. http://dx.doi.org/10.1093/ndt/17.11.2003

[10] Uda, H., Yokota, A., Kobayashi, K., et al. (2006) Two Distinct Clinical Courses of Renal Involvement in Rheumatoid Patients with AA Amyloidosis. The Journal of Rheumatology, 33, 1482-1487. 
Scientific Research Publishing (SCIRP) is one of the largest Open Access journal publishers. It is currently publishing more than 200 open access, online, peer-reviewed journals covering a wide range of academic disciplines. SCIRP serves the worldwide academic communities and contributes to the progress and application of science with its publication.

Other selected journals from SCIRP are listed as below. Submit your manuscript to us via either submit@scirp.org or Online Submission Portal.
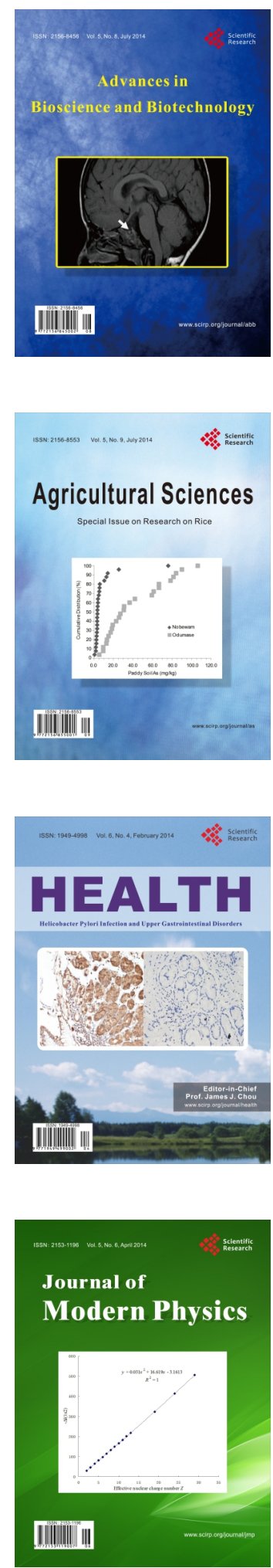
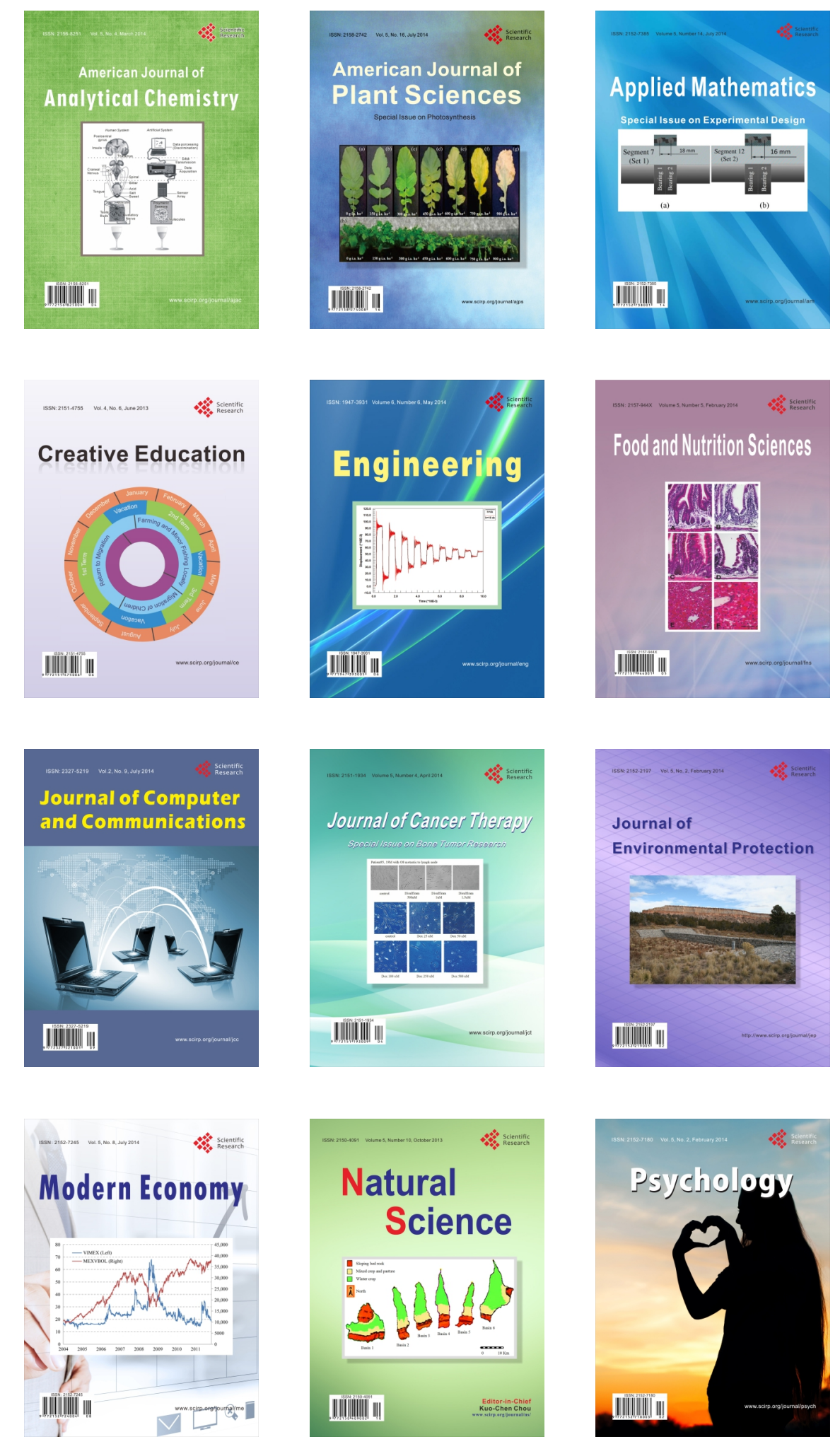